\title{
Concerns, Expectations and Perception Regarding Stature, Physical Appearance and Psychosocial Functioning before and during High-Dose Growth Hormone Treatment of Short Pre-pubertal Children Born Small for Gestational Age
}

\author{
K. Lagrou ${ }^{\mathrm{a}}$ C. Froidecoeur ${ }^{\mathrm{a}}$ M. Thomas ${ }^{\mathrm{a}} \quad$ G. Massa ${ }^{\mathrm{a}, \mathrm{b}}$ D. Beckers ${ }^{\mathrm{c}} \quad$ M. Craen ${ }^{\mathrm{d}}$ \\ C. de Beaufort ${ }^{k}$ R. Rooman ${ }^{\text {e }}$ I. François ${ }^{f} \quad$ C. Heinrichs ${ }^{9}$ M.C. Lebrethon ${ }^{\text {h }}$ \\ G. Thiry-Counson ${ }^{i}$ M. Maes j J. De Schepperk
}

a Belgian Study Group for Pediatric Endocrinology (BSGPE); ${ }^{b}$ Department of Pediatrics, Virga Jesseziekenhuis, Hasselt, and University Hospitals of ${ }^{\mathrm{C}}$ Mont-Godine, ${ }^{\mathrm{d}}$ Gent, ${ }^{\mathrm{e}}$ Antwerpen, ${ }^{\mathrm{f}}$ Leuven, ${ }^{9}$ Bruxelles, hLiège, 'Louvain,

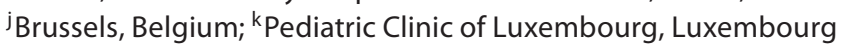

\section{Key Words}

Intrauterine growth retardation $\cdot$ Growth hormone treatment $\cdot$ Perception of stature $\cdot$ Growth expectations . Psychosocial functioning

\begin{abstract}
Background/Aims: Few data are available about parental concerns and psychosocial functioning of young children born small for gestational age (SGA) treated with growth hormone $(\mathrm{GH})$. The present study focused on the perception of short stature and the concerns and expectations of the parents regarding GH treatment. Methods: Forty prepubertal short SGA children, randomized into a GH-treated and a GH-untreated group, and their parents were evaluated by a questionnaire and a semi-structured interview at start and after 2 years of follow-up. Results: Before start, $85 \%$ of the parents were concerned about short stature, $76 \%$ expected an increase in adult height of $\geq 10 \mathrm{~cm}$ and $81 \%$ expected a positive impact on well-being. Half of the parents expressed fears regarding GH treatment. After 2 years, more parents of treated children reported obvious growth and physical changes, and fewer parents reported teasing because of
\end{abstract}

short stature. An improvement of well-being was reported by half of the parents of treated and untreated children. Fears about GH treatment disappeared almost completely. Conclusion: The perspective of GH treatment induced major adult height expectations. In treated children, the physical effects of GH treatment became obvious, teasing because of short stature decreased and initial concerns about short stature and GH therapy decreased.

Copyright $\odot 2008$ S. Karger AG, Basel

\section{Introduction}

Children born small for gestational age (SGA) remain short of stature in up to $10-15 \%$ of cases, and present to varying degrees with difficulties in neurological, sensory-motor and cognitive development [1-5]. Several shortterm and long-term studies have shown a beneficial effect of growth hormone (GH) therapy on growth in the majority of these short SGA children [6-9].

To our knowledge, few data are available on how young children and their parents perceive short stature and the growth-promoting effects of GH treatment, or whether 
the children tolerate this treatment well or not [10-12]. Moreover, findings in SGA children might be different from other conditions associated with short stature, given the associated health and developmental problems in SGA children $[13,14]$ and the potential association with the educational and socioeconomic status of the parents $[3,15-17]$. We hypothesized that these concerns and expectations might be influenced by the presence of health and developmental problems in the child as well as by the mother's height, weight, educational level and socioeconomic status.

In the present study we evaluated in young short SGA children the parents' and children's perception of short stature, their perception of the effects of GH treatment on growth, physical appearance and psychosocial functioning, the parental concerns and expectations regarding $\mathrm{GH}$ treatment, and the psychological tolerance of $\mathrm{GH}$ treatment by the child. In addition, potential associations were investigated between parental expectations and concerns regarding GH treatment on the one hand and the auxological and clinical characteristics of the child and the clinical, demographic and socioeconomic status of the mother on the other.

\section{Patients and Methods}

\section{Patients}

Over an inclusion period of 1.5 years, 40 prepubertal children (18 boys), from among the SGA children consulting for short stature in the paediatric departments of 10 Belgian and 1 Luxembourg hospital centres, were recruited for this study. The inclusion criteria were birth weight and/or length below -2 SD for gestational age [18], chronological age between 3 and 8 years, current height below $-2.5 \mathrm{SD}$ [19] and a height velocity standard deviation scores (SDS) below +1.0 SD during the last 6 to 18 months [20]. The exclusion criteria were gestational age below 34 weeks, endocrine disease including GH deficiency, bone disease, severe chronic disease, Turner, Noonan or Down syndrome or other genetically confirmed syndromes, chromosomal abnormalities, current or previous irradiation therapy, current or previous (up to 18 months before inclusion) treatment with glucocorticoids and severe mental retardation (IQ $\leq 50$ ).

Children were randomized into a treated (TR) group $(n=20)$ and an untreated group (UTR) group $(n=20)$ taking into account the following parameters: gender, chronological age, weight SDS and study centre. Based on a 0.8 power to detect a significant difference $(p=0.05), 20$ subjects in each group were required, assuming a difference of $2 \mathrm{~cm}$ /year in height velocity and a standard deviation of $2.2 \mathrm{~cm} /$ year. For ethical reasons the untreated group did not receive daily placebo injections but underwent the same investigations. The treated children received biosynthetic human $\mathrm{GH}$ (Genotonorm ${ }^{\circledR}$, Pfizer Inc, Belgium) for 2 years in a dosage of $0.066 \mathrm{mg} / \mathrm{kg} \cdot$ day. One treated patient dropped out of the study after 1 year because of family problems. Written informed con- sent was obtained from the parents before enrolment in the study. The ethical review board of each participating centre approved the study protocol.

\section{Methods}

The standard auxological assessment consisted of height, weight and head circumference measurements every 6 months by the same clinical monitor (M.T.). Height, weight, BMI and head circumference SDS were calculated using the British references [19]. The psychological evaluation was performed at the start of the study (T0), without parents and child knowing whether GH therapy was going to be started immediately or after 2 years, and after 2 years of follow-up (T2). A questionnaire for the parents and a semi-structured interview for the child and the parents were developed for the study.

From the questionnaire completed by the parents at T0, general information about the child's clinical and mother's educational, professional and socioeconomic status was obtained. Parents were asked which adult height they expected for their child with and without GH treatment, and which expectations and fears they had with respect to GH treatment. The parental expectations and fears regarding GH treatment were evaluated on the basis of a 4-point Likert scale (not at all, somewhat, a lot, very much). The expectations concerned, in addition to the growthpromoting effect of $\mathrm{GH}$ treatment, a potential positive or negative effect on how the child feels (psychological well-being). The fears referred to difficulties to maintain the treatment for the child and for the parents, difficulties regarding the administration of the injections (preparation, pain, daily constraint, duration) as well as fear of side effects.

On the basis of a semi-structured interview with the parents and the child (where possible, given the young age and delay in cognitive development in some cases) the following parameters were assessed: the perception of short stature and difficulties experienced with it; the previous and current health and developmental problems and psychosocial functioning (in particular how the child feels and teasing by peers). The same parameters were evaluated at T0 and at T2 in the TR as well as in the UTR group, using equivalent adapted questions for the UTR group (regarding growth, physical changes and how the child feels). In addition, parents were asked whether they observed changes with respect to the above-mentioned parameters after 2 years compared to the start. The children were asked whether being small was annoying and why, on the basis of a 4-point Likert scale (from not at all to very much). After 2 years, the perception of GH treatment was evaluated in both parents and children. Parents were questioned about the difficulties to maintain the treatment, difficulties regarding the administration of the injections (preparation, pain, daily constraints, long duration of treatment), fear of side effects and their compliance to the $\mathrm{GH}$ treatment. The children were asked whether the injections were difficult to maintain, painful or annoying or whether they became a habit, on the basis of a 4-point Likert scale (from not at all to very much.)

The perception of the effects of GH treatment on linear growth and other physical changes (less baby-face, looking more mature or older) were assessed in parents and children with the aid of a photograph of the child taken at each evaluation. Satisfaction with the effect of GH treatment was investigated by asking the parents to give a satisfaction score on the basis of a 7-point Likert 
Table 1. Auxological data of the GH-treated (TR) and untreated (UTR) children at birth and at start of the study (T0) and after 2 years (T2)

\begin{tabular}{lcccc}
\hline & $\begin{array}{l}\text { Total group } \\
(\mathrm{n}=40)\end{array}$ & $\begin{array}{l}\text { TR group } \\
(\mathrm{n}=20)\end{array}$ & $\begin{array}{l}\text { UTR group } \\
\left(\mathrm{n}=20^{*}\right)\end{array}$ & $\mathrm{p}$ \\
\hline $\begin{array}{l}\text { Neonatal data } \\
\quad \text { Birth weight (SDS) }\end{array}$ & $-2.7 \pm 0.8$ & $-2.7 \pm 0.9$ & $-2.6 \pm 0.8$ & $\mathrm{~ns}$ \\
$\quad$ Gestational age, weeks & $37.7 \pm 1.9$ & $37.3 \pm 2.1$ & $38.2 \pm 1.6$ & $\mathrm{~ns}$ \\
Data at start & $5.3 \pm 1.5$ & $5.5 \pm 1.6$ & $5.1 \pm 1.3$ & $\mathrm{~ns}$ \\
$\quad$ Age, years & $-3.3 \pm 0.8$ & $-3.3 \pm 0.6$ & $-3.2 \pm 0.9$ & $\mathrm{~ns}$ \\
$\quad$ Height (SDS) & $-3.8 \pm 1.4$ & $-3.8 \pm 1.3$ & $-3.9 \pm 1.4$ & $\mathrm{~ns}$ \\
$\quad$ Weight (SDS) & $-1.9 \pm 1.3$ & $-1.7 \pm 1.1$ & $-2.0 \pm 1.5$ & $\mathrm{~ns}$ \\
$\quad$ BMI (SDS) & $-2.7 \pm 1.5$ & $-2.7 \pm 1.4$ & $-2.8 \pm 1.6$ & $\mathrm{~ns}$ \\
$\quad$ Head circumference (SDS) & & & $-3.1 \pm 0.9$ & $<0.001$ \\
Data after 2 years & $-2.4 \pm 0.9$ & $-1.9 \pm 0.7$ & $-3.7 \pm 1.5$ & $<0.01$ \\
$\quad$ Height (SDS) & $-3.0 \pm 1.5$ & $-2.3 \pm 1.2$ & -3.5 \\
$\quad$ Weight (SDS) & $-1.7 \pm 1.3$ & $-1.5 \pm 1.1$ & $-2.0 \pm 1.5$ & $\mathrm{~ns}$ \\
BMI (SDS) & $-2.4 \pm 1.5$ & $-2.0 \pm 1.4$ & $-2.8 \pm 1.5$ & $<0.05$ \\
$\quad$ Head circumference (SDS) & & & \\
\hline
\end{tabular}

Values are means $\pm \mathrm{SD} .{ }^{*} \mathrm{n}=19$ for data after 2 years. scale (from not satisfied at all to very satisfied). The compliance to $\mathrm{GH}$ treatment was evaluated by asking the parents how frequently they had forgotten to give the injections on a 4-point Likert scale (from never to often). Parents who answered that they had forgotten to give the injections were questioned about the real frequency (how many times for the past year).

For each of the responses of both children and parents, any differences between treated and untreated children were investigated at T0 as well as at T2. Answers to some items of the interview are lacking for some children and parents mainly because of the young age of the child.

In addition, the influence of the child's clinical characteristics (gender, preschoolers or school-age, presence of minor dysmorphic features, current health problems, developmental delay and need of specialized care at start of the study) on the auxological parameters were examined at T0 and at T2. Potential associations with the auxological parameters of the child were studied by dividing the following variables into tertiles: birth weight SDS, height SDS, BMI SDS and head circumference SDS at start.

In order to study potential maternal influences, the mothers' auxological and demographic characteristics at start of the study were taken into account. The mothers' ages, heights and BMIs were divided into tertiles. The auxological data of 2 adoptive and 2 foster mothers were not included in the analysis. The mothers' demographic characteristics comprised educational status, evaluated according to 3 levels: low, medium, high; professional status, covering working (5 categories) or not working situation (2 categories); and socioeconomic status or financial situation at home, evaluated according to 3 levels (difficult, short of cash, no problem).

Potential associations were investigated between initial parental concerns about short stature, initial fears with respect to GH treatment and parents' expectations regarding the effects of $\mathrm{GH}$ treatment and the child's and mother's auxological and clinical characteristics at start.
Statistical Analysis

Clinical and auxological results are expressed as means $\pm \mathrm{SD}$, interview data as absolute numbers and percentages. Differences of continuous variables between subgroups were evaluated by Student's unpaired t test or by the Mann-Whitney U test as appropriate, and differences of categorical variables by the $\chi^{2}$ test or by Fisher's exact test as appropriate at T0 and at T2. Changes in auxological results were evaluated by Student's paired $t$ test, and changes in interview data by the $\chi^{2}$ test or by Fisher's exact test as appropriate. The level of significance of difference was set at $\mathrm{p}<$ 0.05 . Statistical analysis was performed using SPSS software (version 12, SPSS Inc., USA).

\section{Results}

\section{Auxological, Clinical and Demographic \\ Characteristics of the Children}

Table 1 shows the auxological data at $\mathrm{T} 0$ and at T2. Chronological ages at the start of the study ranged between 3.2 and 7.8 years. At T0 there were no differences in the auxological parameters between the TR and the UTR patients. After 2 years of GH therapy, the patients of the TR group were significantly taller $(-1.9 \pm 0.7$ SDS vs. $-3.1 \pm 0.9$ SDS; $p<0.001)$ and heavier $(-2.3 \pm 1.2$ SDS vs. $-3.7 \pm 1.5$ SDS; $\mathrm{p}<0.01)$, and had a larger head circumference $(-2.0 \pm 1.4$ SDS vs. $-2.8 \pm 1.6$ SDS; $p<$ $0.05)$. None of the patients entered puberty during the study period.

The clinical data of the children are presented in table 2. Eight (20\%) children presented minor dysmorphic features, suggestive of Silver-Russell syndrome $(\mathrm{n}=3)$, 
Table 2. Clinical characteristics of the GH-treated (TR) and untreated (UTR) children at start (T0) and after 2 years (T2)

\begin{tabular}{lrrr}
\hline & Total group & TR group & UTR group \\
\hline At start & & & \\
$\quad$ Dysmorphic features & $8 / 40(20)$ & $3 / 20(15)$ & $5 / 20(25)$ \\
Chronic health problems & $9 / 39(23)$ & $4 / 19(21)$ & $5 / 20(25)$ \\
$\quad$ Developmental problems & $18 / 36(50)$ & $8 / 18(47)$ & $10 / 18(53)$ \\
$\quad$ Specialized care needed & $12 / 36(30)$ & $5 / 18(28)$ & $7 / 18(39)$ \\
After 2 years & & & \\
$\quad$ Developmental problems & $14 / 39(36)$ & $7 / 19(37)$ & $7 / 20(35)$ \\
Specialized care needed & $14 / 39(36)$ & $7 / 19(37)$ & $7 / 20(35)$ \\
\hline
\end{tabular}

Results are expressed as the number of children with the respective problem. Figures in parentheses are percentages.
3-M syndrome ( $\mathrm{n}=1)$, Renpenning syndrome $(\mathrm{n}=1)$ or another non-specified genetic syndrome $(n=3)$. Children with dysmorphic features had a lower birth weight $(-3.5 \pm 1.1$ SDS vs. $-2.5 \pm 0.6$ SDS; $\mathrm{p}<0.005)$. At T0, parents reported chronic health problems in $9 / 39$ (23\%) of the children, mainly recurrent respiratory, digestive and orthopaedic problems. Half of the SGA children had developmental problems, defined as a delay in learning to walk and talk and in toilet training. Birth weight was lower in these children $(-3.0 \pm 1.1$ SDS vs. $-2.3 \pm 0.4$ SDS; $\mathrm{p}<0.005)$. Twelve of the $36(30 \%)$ children needed specialized care (physical, speech or psychomotor therapy) at T0. No differences were observed between the TR and UTR group.

At start of the study, some auxological parameters were related to the clinical characteristics. Children with dysmorphic features had a lower height $(-3.8 \pm 1.2$ SDS vs. $-3.1 \pm 0.6$ SDS; $\mathrm{p}<0.05)$ and BMI $(-3.0 \pm 1.7$ SDS vs. $-1.6 \pm 1.1$ SDS; $\mathrm{p}<0.05)$. Children with developmental problems had a lower BMI $(-2.4 \pm 1.3$ SDS vs. $-1.3 \pm$ 1.2 SDS; $\mathrm{p}<0.05)$ and smaller head circumference $(-3.7$ \pm 1.5 SDS vs. $-1.8 \pm 1.1$ SDS; $\mathrm{p}<0.001)$. Children who needed specialized care had a smaller head circumference $(-3.6 \pm 1.7$ SDS vs. $-2.4 \pm 1.4$ SDS; $\mathrm{p}<0.05)$.

\section{Auxological and Demographic Characteristics of the Mothers}

The auxological and demographic data of the mothers of the studied children are shown in table 3. The mothers' mean height was significantly below the population mean $(157.1 \pm 5.7 \mathrm{~cm} ;-1.1 \pm 1.0$ SDS). Five women were smaller than the $3 \mathrm{rd}$ percentile. Three women were overweight $\left(\mathrm{BMI}>25 \mathrm{~kg} / \mathrm{m}^{2}\right), 1$ was obese $\left(\mathrm{BMI}>30 \mathrm{~kg} / \mathrm{m}^{2}\right)$, and 5 women were underweight $\left(\mathrm{BMI}<18.5 \mathrm{~kg} / \mathrm{m}^{2}\right)$. The mothers' educational status (low, medium, high) was evenly
Table 3. Auxological and demographic characteristics of the mothers of GH-treated (TR) and untreated (UTR) children

\begin{tabular}{|c|c|c|c|}
\hline & All patients & TR Group & UTR Group \\
\hline \multicolumn{4}{|c|}{ Mothers' auxological characteristics ${ }^{1}$} \\
\hline Age, years & $32.7 \pm 3.7$ & $32.9 \pm 3.7$ & $32.4 \pm 3.8$ \\
\hline Height, cm & $157.1 \pm 5.7$ & $155.1 \pm 7.6$ & $159.1 \pm 5.0$ \\
\hline Weight, kg & $52.1 \pm 9.3$ & $49.7 \pm 7.6$ & $54.4 \pm 10.4$ \\
\hline BMI, $\mathrm{kg} / \mathrm{m}^{2}$ & $21.0 \pm 3.2$ & $20.7 \pm 2.9$ & $21.4 \pm 3.5$ \\
\hline \multicolumn{4}{|c|}{ Mothers' demographic characteristics ${ }^{2}$} \\
\hline \multicolumn{4}{|c|}{ Educational status } \\
\hline Low & $14 / 40(35)$ & $7 / 20(35)$ & $7 / 20(35)$ \\
\hline Medium & $13 / 40(32.5)$ & $7 / 20(35)$ & $6 / 20(30)$ \\
\hline High & $13 / 40(32.5)$ & $6 / 20(30)$ & $7 / 20(35)$ \\
\hline \multicolumn{4}{|l|}{ Professional status } \\
\hline Working & $24 / 40(60)$ & $11 / 20(55)$ & $13 / 20(65)$ \\
\hline Without work & $16 / 40(40)$ & $9 / 20(45)$ & $7 / 20(35)$ \\
\hline \multicolumn{4}{|c|}{ Working categories: } \\
\hline 1 employee & 13 & 6 & 7 \\
\hline 2 independent & 2 & 2 & 0 \\
\hline 3 employer & 0 & 0 & 0 \\
\hline 4 functionary & 2 & 0 & 2 \\
\hline 5 labourer & 6 & 3 & 3 \\
\hline \multicolumn{4}{|l|}{ Without work: } \\
\hline 1 housewife & 13 & 7 & 6 \\
\hline 2 unemployed & 3 & 2 & 1 \\
\hline \multicolumn{4}{|l|}{ Financial situation } \\
\hline Difficult & $2 / 40(5)$ & $1 / 20(5)$ & $1 / 20(5)$ \\
\hline Short of cash & $8 / 40(20)$ & $3 / 20(15)$ & $5 / 20(25)$ \\
\hline No problem & $30 / 40(75)$ & $16 / 20(80)$ & $14 / 20(70)$ \\
\hline
\end{tabular}

Horm Res 2008;69:334-342 
Table 4. Perception of short stature (SS), growth and psychosocial functioning at start and after 2 years in GHtreated (TR) and untreated (UTR) children

\begin{tabular}{|c|c|c|c|c|}
\hline & Total group & TR group & UTR group & $\mathrm{p}$ \\
\hline \multicolumn{5}{|c|}{$\begin{array}{l}\text { Perception of and concerns about SS and well-being at start } \\
\text { According to parents }\end{array}$} \\
\hline Concerned about SS & $33 / 39(85)$ & $19 / 19(100)$ & $14 / 20(70)$ & $<0.05$ \\
\hline Child teased by peers because of SS & $12 / 39(31)$ & $7 / 20(35)$ & $5 / 19(26)$ & ns \\
\hline \multicolumn{5}{|l|}{ According to the child } \\
\hline Annoyed by SS & $14 / 37(38)$ & $5 / 19(26)$ & $9 / 18(50)$ & ns \\
\hline \multicolumn{5}{|c|}{ Perception of changes in height and physical appearance after 2 years } \\
\hline \multicolumn{5}{|c|}{ According to parents } \\
\hline Concerns about SS & $14 / 39(36)$ & $5 / 19(26)$ & $9 / 20(45)$ & ns \\
\hline Child has grown & $29 / 36(80)$ & $17 / 17(100)$ & $12 / 19(31)$ & $<0.05$ \\
\hline Child has physically changed & $22 / 30(73)$ & $15 / 16(94)$ & $7 / 14(50)$ & $<0.05$ \\
\hline Child has become stronger & $16 / 38(42)$ & $11 / 18(61)$ & $5 / 20(25)$ & $<0.05$ \\
\hline \multicolumn{5}{|l|}{ According to the child } \\
\hline Annoyed by SS & $14 / 36(39)$ & 2/16 (12) & $12 / 20(60)$ & $<0.05$ \\
\hline Obviously grown & $19 / 34(56)$ & $17 / 17(100)$ & $12 / 17(71)$ & $<0.05$ \\
\hline \multicolumn{5}{|c|}{ Perception of changes in psychosocial functioning after 2 years } \\
\hline Child teased because of SS & $11 / 39(28)$ & $2 / 19(10)$ & $9 / 20(45)$ & $<0.05$ \\
\hline Child feels better & $20 / 39(51)$ & $9 / 19(47)$ & $11 / 20(55)$ & ns \\
\hline
\end{tabular}

distributed. Twenty-four (60\%) mothers were working and $30(75 \%)$ reported that they did not have any financial problems. No differences were found between mothers of treated and untreated children.

\section{Perception of and Concerns about Short Stature at}

Start of the Study

Thirty-three (85\%) parents were concerned about the short stature of their child, and according to 12 (31\%) parents their child was teased because of short stature. Fourteen $(38 \%)$ children reported being annoyed by their stature. Parental concerns about the short stature of the child were not related to any of the auxological or clinical characteristics of the child, nor to the auxological or demographic characteristics of the mothers (Table 4).

\section{Expectations and Fears Regarding GH Therapy at Start of the Study}

Before the start of GH treatment, 30 (76\%) parents expected a gain in adult height of at least $10 \mathrm{~cm} ; 11(27 \%)$ of them expected even $18 \mathrm{~cm}$ or more. Median expected height gain was $12 \mathrm{~cm}$ (range: $0-40 \mathrm{~cm}$ ) and was similar for boys and girls. For boys, parents expected an adult height of $169.9 \pm 6.1 \mathrm{~cm}$ with and of $156.9 \pm 8.5 \mathrm{~cm}$ without GH treatment and for girls an adult height of $160.1 \pm 6.9 \mathrm{~cm}$ with and of $146.1 \pm 13.0 \mathrm{~cm}$ without $\mathrm{GH}$ treatment. Thirty-two (80\%) parents expected an improvement of the child's psychological well-being.

Expectations of an adult height gain of more than 18 $\mathrm{cm}$ were more frequently observed in parents of children with a lower birth weight ( $60 \%$ in children with the lowest birth weight SDS vs. 9\% in children with the highest birth weight SDS tertile; $p<0.05$ ), and in parents of children who received specialized care $(55 \%$ when the child received specialized care vs. $24 \%$ when the child did not receive specialized care; $\mathrm{p}<0.05$ ).

The evaluation of fears regarding GH treatment revealed that painfulness of injections and potential side effects due to GH treatment were the most frequently reported constraints (18 and 20 parents, respectively). Parents were more frequently concerned about side effects in girls (73\% of the parents of girls versus $18 \%$ of parents of boys; $\mathrm{p}<0.005)$ and in children with a higher height at start $(82 \%$ of the parents of children with the highest 
height SDS tertile vs. $36 \%$ of the parents of children with the lowest height SDS tertile; $\mathrm{p}<0.05)$. Mothers with a higher socioeconomic status (SES) were more concerned about side effects ( $57 \%$ of the mothers with the highest SES vs. $22 \%$ with the lowest SES; $p=0.05)$ and painfulness of injections ( $50 \%$ of the mothers with the highest SES vs. $30 \%$ with the lowest SES; $\mathrm{p}<0.05$ ).

Perception of Changes in Height, Physical Appearance and Psychosocial Functioning after 2 Years

Five (26\%) parents of GH-treated children and 9 (45\%) parents of untreated children were still concerned about the stature of their child. Changes in body size and physical appearance were more obvious for parents of treated children than for parents of untreated children, as evaluated by the following parameters: obvious growth (100 vs. $31 \%$; $\mathrm{p}<0.05)$, physical changes ( 94 vs. $50 \%$; p < 0.05$)$ and increased strength (61 vs. $25 \%$; p < 0.05). After 2 years, a smaller number of treated children reported being still annoyed by stature (12 vs. $60 \%$ in the untreated group, $\mathrm{p}<0.05)$. All GH-treated children reported that they had obviously grown (100 vs. $71 \%$ of the untreated children, $\mathrm{p}<0.05)$.

With respect to psychosocial functioning, a smaller number of parents reported teasing by peers after 2 years when the child was treated ( 10 vs. $45 \%$; $p<0.05$ ). Regarding changes in psychological well-being, half of the parents of the treated (47\%) and of the untreated children (55\%) reported an increase in self-confidence and/or improvement of self-esteem (table 4).

\section{Tolerance of GH Treatment}

After 2 years of GH treatment, only 2 of 19 (10\%) parents reported fears of side effects compared to 9/20 (49\%) before the start of GH treatment. Regarding the acceptance of GH treatment, all parents thought that the injections had become a habit for the child, and none of them thought that the injections were still painful after 2 years, in contrast to $45 \%$ of the parents reporting that the injections had been painful for their child in the beginning, i.e. the first weeks. After 2 years, the injections had become a habit for $83 \%$ of the children, but $59 \%$ of the children still found the injections somewhat painful. Parent's reporting on how the child accepted GH treatment was not significantly different for preschool children compared to school-age children.

Regarding the compliance with GH treatment after 2 years, 4 of the 19 (21\%) parents of treated children reported that they never forgot to give the injections, 13/19 (68\%) reported that they rarely forgot the injections and none of the parents reported that they often forgot the injections. All parents gave a very high satisfaction score (6 or 7 ) with respect to GH treatment.

\section{Discussion}

This study describes the concerns about short stature and the concerns and expectations about GH treatment, as well as the perception of the physical and psychological effects of GH treatment in young short SGA children, on the basis of a questionnaire for the parents and an extensive interview with the parents and the child.

A first interesting finding is that, although consulting a paediatric endocrinologist and participating in a growth-promoting study, $15 \%$ of the parents were not concerned about the short stature of their child. Taking into account that, at start of the study, half of the children had developmental problems and one quarter suffered from chronic health problems, we cannot exclude that these problems resulted in contacting a physician who drew attention to the short stature. It is, however, noteworthy that parents' initial concerns about the short stature of their child were not influenced by the health or developmental status of the child. Another explanation could be that not all parents were aware of the limited adult height expectations for their child before referral. Furthermore, only one third of the children themselves worried about their short stature. In a previous study in children with Turner syndrome, we observed that children younger than 6 years did not perceive their short stature as a problem [12]. Moreover, the social impact of short stature at this young age is limited and previous studies in short-stature children even reported some positive social experiences in early childhood $[21,22]$.

Even though concerns about short stature were not present in all parents, expectations of increased adult height were high. Three quarters of the parents expected an adult height gain of $10 \mathrm{~cm}$ or more, and 1 quarter of the parents $18 \mathrm{~cm}$ or more. Unrealistic future height expectations at the start of GH therapy have been reported previously in patients with Turner syndrome and their parents [12, 23]. In our study, parental adult height expectations were influenced by some of the auxological characteristics of the child: a low birth weight and a small head circumference, linked to the need of specialized care in our population, were associated with higher adult height expectations. The confrontation with developmental problems in the child from early childhood could increase the awareness for the need of treatment as well 
as increase the hope and expectations regarding the potential effects of treatment.

A third finding in this study was that parents of short SGA children had high expectations regarding not only the growth promoting effects, but also the psychological effects of GH therapy: $81 \%$ of the parents expected an improvement how the child feels, predominantly an increase of self-confidence and an improvement of self-esteem. As far as we know, the parental expectations regarding potential psychological effects of $\mathrm{GH}$ treatment have not been studied. The parental expectations of an improved well-being could probably be understood against the background of the general assumption in Western society that short stature is socially disadvantageous [21, 24, 25]. Moreover, the expected catch-up growth induced by GH treatment could result in a stature more in accordance with chronological age as well as in a decrease in the height difference compared to peers, resulting in a better psychosocial adaptation.

Of note, despite the expectations of improved well-being, the perspective of GH treatment also induced fears in half of the parents at the start of therapy, mainly because of painfulness of injections and potential side effects. Parents were obviously more concerned about side effects in girls than in boys. Several studies provide evidence replicating the societal bias that taller stature is more important in boys than in girls [26]. As a consequence, parents might be less tolerant of potential side effects and constraints associated with GH treatment, and less ready to take risks in girls than in boys. Parents were also more concerned about side effects in children with less growth retardation. A similar reasoning could be applied, i.e. parents probably are more sceptical about treatment if the need is less. Fear of side effects and painfulness of injections were more present in mothers with a higher socio-economic status. We hypothesize that mothers with a higher socio-economic status probably question their doctor more about the potential constraints of GH treatment, and tend to obtain complementary information or a second opinion by other ways, such as the internet or their private network of relations.

After 2 years, fewer parents and children were concerned by short stature, in the GH-treated as well as in the untreated group. These findings are in line with the only 2 studies published up to now, evaluating the children's attitudes and emotional adjustment to shortness during $\mathrm{GH}$ therapy and demonstrating that $\mathrm{GH}$ treatment had a beneficial effect on children's attitudes to being short $[10,11]$. The improvement of psychological wellbeing as reported by half of the parents of treated as well as untreated children after 2 years, irrespective of current height and/or growth status, is partially in line with the findings of other studies in short normal children demonstrating a lack of difference in self-esteem and quality of life between GH-treated and untreated children [27, 28]. The improvement in well-being could be due to an attention effect: the feeling of greater emotional support as well as of attention paid to the problem of short stature by the parents and medical team, leading to a reduction of emotional distress associated with short stature. The perspective of treatment after 2 years of follow-up might have been a bias for the evaluation of the untreated group.

With respect to social contact, a considerable number of parents reported teasing by peers because of short stature at the start of the study. In line with the findings of Tanaka et al. [11] in GH-treated SGA children a decline was observed after 2 years of GH therapy. Several authors published convincing evidence that short stature is an important factor in interactions with peers, children with significantly short stature being more vulnerable to diverse developmental, social and educational problems [22, 24, 25, 29-32]. Some critical studies stressed the risk of inappropriately attributing problems of behavioural and emotional adjustment exclusively to short stature and, depending on the author, diverse factors were put forward as crucial determinants of behavioural and emotional problems such as social class [33], cognitive abilities [21], the underlying medical condition [34], and referral to clinic because of short stature [35]. Undoubtedly, catch-up growth in children with short stature might positively influence the social interactions directly through the positive reactions about the obvious growth by peers and adults, and indirectly by enhancing the child's self-esteem and the way the child likes himself, as well as by being treated more according to his chronological age [32]. Our findings of a positive impact of GH treatment on emotional and social functioning are in line with the findings of other studies in children with short stature due to other reasons than intra-uterine growth retardation $[23,36,37]$. Up to now, few studies have been published on the psychological effects of GH treatment in SGA children $[11,38,39]$. Van der Reijden-Lakeman et al. [38] demonstrated a beneficial effect on attention capacity, and a significant increase in general self-esteem and social acceptance after 2 years of GH therapy. Van Pareren et al. [39] reported a significant improvement of behaviour and self-perception after long-term GH treatment. 
In our study, satisfaction with GH therapy was high, with respect to both growth promoting effects and psychological tolerance. Parental initial fears for side effects and painfulness of injections disappeared almost completely once GH treatment was started and compliance, as reported by the parents, was very good. Although the injections caused problems in half of the families during the first weeks, they subsequently became a habit for the majority of children. After 2 years, $\mathrm{GH}$ treatment was experienced more positively by the parents than by the children themselves. Moreover, parents tended to underestimate the burden for the child, since the parents thought that the injections were not painful anymore after 2 years, whereas for two thirds of the children the injections were still somewhat painful. Tanaka [11] reported similar observations in GH-treated SGA children but a less positive evaluation in parents, i.e. discomfort during GH treatment was experienced by one third of the children and parents.

Some caution is needed in the interpretation of the results of our study. Despite an inclusion period of $1 \frac{1}{2}$ years, and a nation wide recruitment, only a limited number of patients could be recruited for this study, limiting its statistical power, especially in the subgroup analysis. The subgroup analysis should be treated with scepticism irrespective of its statistical significance. Another weakness of our study design is that most of the studied patients were referred to a university hospital. Pre-referral counselling, which was not studied by us, might have influenced the concerns and expectations of the parents, despite the fact that in each centre an equal number of untreated and treated subjects was obtained by including the centre in the stratified randomization. Moreover, the perspective of GH treatment after 2 years of follow-up of the untreated group could have been a bias and as such weakened the strength of having a control group. Because this trial was not conducted double-blind, we cannot exclude the Hawthorne effect (the phenomenon that subjects, when observed in a study, temporarily change their behaviour or performance), as a major bias, despite the fact that the analysis was performed after 2 years. Due to the young age of the study group several answers are lacking in the children's reporting, and we were forced to rely mainly upon the parents' reporting. Also, no strict compliance monitoring was performed in our study and the results depend on the parents' reporting, although the growth response in the treated children was always above the growth increment found in untreated patients. Another potential weakness is that preterm SGA children with a gestational age below 34 weeks, who might present a considerable part of short SGA infants proposed for GH therapy in daily clinical practice, were not studied by us. However, preterm short SGA children present a different postnatal growth pattern, and have other morbidities during infancy and childhood than term short SGA children do. We cannot exclude that concerns, expectations and perceptions regarding stature, physical appearance and psychosocial functioning might be different in this specific population.

In conclusion, the majority of parents were concerned about the short stature of their SGA child, and the perspective of GH treatment induced major adult height expectations. Parental concerns about short stature were related neither to the health and developmental status of the child nor to the maternal auxological or demographic parameters, whereas adult height expectations were related to the child's birth weight and developmental status. Before the start of GH treatment, fears about side effects and painfulness of injections were present in half of the parents. Once GH treatment was started, concerns about short stature and fears about GH treatment decreased. Improvement of how the child feels was observed in half of both treated and untreated children, irrespective of their change in height. Changes in physical appearance were obvious for treated children and their parents. Children and parents reported that GH injections were physically and emotionally rather well tolerated.

\section{Acknowledgements}

This study was supported by a grant of the Belgian Study Group for Paediatric Endocrinology. The growth hormone (Genotonorm) was provided by Pfizer, Belgium. The authors express their thanks to all the members of the BSGPE who proposed patients to participate in this study.

References 
$\checkmark 4$ Smedler AC, Faxelius G, Bremme K, Lagerstrom M: Psychological development in children born after severe intrauterine growth retardation: a 10-year follow-up. Acta Paediatr 1992;81:197-203.

5 Strauss RS: Adult functional outcome of those born small for gestational age: twentysix year follow-up of the 1970 British birth cohort. JAMA 2000;283:625-632.

$\checkmark 6$ Carel JC, Chatelain P, Rochiccioli P, Chaussain JL: Improvement in adult height after growth hormone treatment in adolescents with short stature born small for gestational age: Results of a randomized controlled study. J Clin Endocrinol Metab 2003;88: 1587-1593.

$\checkmark 7$ Ahlgren J, Albertsson Wikland K: Final height in short children born small for gestational age treated with growth hormone. Pediatr Res 2004;57:216-222.

$>8$ de Zegher F, Du Caju M, Heinrichs C, Maes M, De Schepper J, Craen M, Vanweser K, Malvaux P, Rosenfeld RG: Early, discontinuous, high dose growth hormone treatment to normalize height and weight of short children born small for gestational age: results over 6 years. J Clin Endocrinol Metab 1999; 84:1558-1561.

-9 Van Pareren Y, Mulder P, Houdijk M, Jansen M, Reeser M, Hokken-Koelega A: Adult height after long term, continuous growth hormone $(\mathrm{GH})$ treatment in short children born small for gestational age: results of a randomized, double-blind, dose-response GH trial. J Clin Endocrinol Metab 2003;88: 3584-3590.

10 Boulton TJC, Dunn SM, Quigley CA: Perceptions of self and short stature: effects of two years of growth hormone treatment. Acta Paediatr Scand 1991;377:20-27.

- 11 Tanaka T, Matsuo N, Seino Y, Fujieda K, Yokoya S, Tachibana K: Growth-promoting and psychological effects of high-dose growth hormone treatment in children with intrauterine growth retardation. Clin Pediatr Endocrinol 2000;9:7-17.

-12 Lagrou K, Xhrouet-Heinrichs D, Craen M, Chanoine JP, Malvaux P, Bourguignon JP: Age-related perception of stature, acceptance of therapy, and psychosocial functioning in human growth hormone-treated girls with Turner's syndrome. J Clin Endocrinol Metab 1998;83:1494-1501.

13 Vik T, Vatten L, Markestad T, Ahksten G, Jacobsen G: Morbidity during the first year of life in small for gestational age infants. Arch Dis Childhood 1996;75:F33-F37.

-14 Hadders-Algra M, Huisjes HJ, Touwen BLC: Preterm or small for gestational age infants. Neurological and behavioural development at the age of 6 years. Eur J Pediatr 1988;147: 460-467.
15 Silverstein JH, Shulman D: Growth hormone for small-for-gestational-age children: short and sweet? J Pediatr 2003;142:91-92.

16 Bacharach VR: Effects of maternal intelligence, marital status, income, and home environment on cognitive development of low birth weight Infants. J Pediatr Psychol 1998; 23:197-205.

17 Jacobsen G, Schei B, Hoffman HJ: Psychosocial factors and small-for-gestational-age infants among parous Scandinavian women. Acta Obstetr Gynecol Scandinavica 1997; 76(suppl 165):14-18.

18 Niklasson A, Ericson A, Fryer JG, Karlberg J, Lawrence C, Karlberg: An update of the Swedish references standards for weight, length and head circumference at birth for given gestational age (1977-1981). Acta Paediatr Scand 1991;80:756-762.

-19 Freeman JV, Cole TJ, Chinn S, Jones PR, White EM, Preece MA: Cross-sectional stature and weight reference curves for the UK, 1990. Arch Dis Child 1995;73:17-24.

20 Tanner JM, Whitehouse RH, Takaishi M: Standards from birth to maturity for height, weight, height velocity and weight velocity: British children 1965. Arch Dis Child 1966; 41:454-471, 613-635.

21 Gilmour J, Skuse D: Short stature - the role of intelligence in psychosocial adjustment. Arch Dis Child 1996;75:25-31.

22 Stathis SL, O'Callaghan MJ, Williams GM, Najman JM, Andersen MJ, Bor W: Behavioral and cognitive associations of short stature at 5 years. J Paediatr Child Health 1999;35: 562-567.

23 Huisman J, Slijper FME, Sinnema G, Akkerhuis GW, Brugman-Boezeman A, Feenstra J, Den Hartog L, Heuvel F: Psychosocial effects of two years of human growth hormone treatment in Turner Syndrome. Horm Res 1993;39:56-59.

24 Siegel PT, Clopper R, Stabler B: Psychological impact of significantly short stature. Acta Paediatr Scand 1991;377:14-18.

25 Siegel PT: Psychological adjustment of short children and normal controls; in Stabler B, Underwood LE (eds): Growth, Stature and Adaptation. An international symposium on the behavioral, social, and cognitive aspects of growth delay. Chapel Hill, University of North Carolina, 1994, pp 123-134.

26 Sandberg DE, Colsman M, Voss LD: Short stature and quality of life: A review of assumptions and evidence; in Pescovitz $\mathrm{OH}$, Eugster E (eds): Pediatric Endocrinology: Mechanisms, Manifestations, and Management. Philadelphia, Lippincot, Williams and Wilkins, 2004, pp 191-202.

27 Downie AB, Mulligan J: Psychological response to growth hormone treatment in short normal children. Arch Dis Childhood 1996;75:32-35.
28 Pilpel D, Leiberman E, Zadik Z, Carel CA: Effect of growth hormone treatment on quality of life of short stature children. Horm Res 1995;44:1-5.

29 Gordon M, Crouthamel C, Post EM, Richman RA: Psychosocial aspects of constitutional short stature: social competence, behavior problems, self-esteem, and family functioning. J Pediatr 1982;101:477-480.

30 Lee PA, Kendig JW, Kerrigan JR: Persistent short stature, other potential outcomes, and the effect of growth hormone treatment in children who are born small for gestational age. Pediatrics 2003;112:150-162.

31 Stabler B, Clopper RR, Siegel PT: Academic achievement and psychological adjustment in short children. Develop Behav Pediatrics 1994;15:1-6.

-32 van der Reijden-Lakeman I, Slijper FME, van Dongen-Melman JEWM, de Waal WJ, Verhulst FC: Self-concept before and after two years of growth hormone treatment in intrauterine growth-retarded children. Horm Res 1996;46:88-94.

33 Downie AB: Are short normal children at a disadvantage? The Wessex growth study. BMJ 1997;314:97-100.

34 Sandberg DE: Short stature: intellectual and behavioral aspects; in Lifshitz F (ed): Pediatric Endocrinology, ed 3. New York, Marcel Dekker, 1996, pp 149-162.

35 Kranzler JH: Is short stature a handicap? A comparison of the psychosocial functioning of referred and nonreferred children with normal short stature. J Pediatr 2000;136:96102.

36 Stabler B, Siegel PT, Clopper RR, Stoppani CE, Compton PG, Underwood LE: Behavior change after growth hormone treatment of children with short stature. J Pediatr 1998; 133:366-373.

-37 Steinhausen HC, Dorr HG, Malin Z: Behavioral evaluation of $\mathrm{GH}$ treatment in short statured children and adolescents: Findings from a pilot study. J Endocrinol Invest 2002; 25:351-356.

38 van der Reijden-Lakeman IEA, de Sonneville LMJ, Swaab-Barneveld HJT, Slijper FME, Verhulst FC: Evaluation of attention before and after two years of growth hormone treatment in intrauterine growth-retarded children. J Clin Experim Neuropsychol 1997;19:101-118.

39 van Pareren YK, Duivenvoorden HJ, Slijper FSM, Koot, HM, Hokken-Koelega ACS: Intelligence and psychosocial functioning during long-term growth hormone therapy in children born small for gestational age. J Clin Endocrinol Metab;2004;89:5295-5302. 